\title{
Volumetric water content measurement probes in earth-dam construction
}

\author{
Michael Bardanis ${ }^{1, a}$ \\ ${ }^{1}$ Edafos Engineering Consultants S.A., Laboratory, 2 Therapion st., 10444 Athens, Greece
}

\begin{abstract}
Two frequency domain reflectometry (FDR) probes have been used. They were used on compacted soils both in the laboratory and in the field. Measurements in the laboratory were intended for calibration. The range of densities and types of materials where insertion of the probes can be achieved was investigated first. The effect of sporadic presence of coarser grains and density on these calibrations, once insertion could be achieved, were investigated second. Measurements on laboratory prepared samples with the same moisture content were different when the sample was kept in the mould from when it was extruded from it. Also both these measurements were different from that in a sample of the same density but significantly larger in diameter. It was found that measurements with these probes are affected by dilation exhibited by soil around the rods of the probes during insertion. Readings immediately after insertion of the sensors on samples extruded from their moulds were the ones closer to measured values. These readings combined with total volume and mass obtained from sand-cone tests during the construction of an earth-dam allowed fairly accurate estimation of the dry unit weight but not the gravimetric water content.
\end{abstract}

\section{Introduction}

Volumetric water content probes have been in use for years in the fields of soil science and lately unsaturated soil mechanics. In the field of soil science their use is limited practically to soft soils and initial density is not a problem for calibration, insertion of probes, and measurement duration. The ability of volumetric water content probes to measure field moisture content appears very appealing for earth-dam construction, where the need to control and measure field moisture and density are critical for appropriate construction. In these cases however, soils of various grain size distributions, densities and strengths may be encountered. The paper discusses the effect of these parameters on using this type of probes.

Volumetric water content measurement methods may be divided in three broad categories; nuclear methods, electromagnetic methods, and indirect measurement methods based on the direct or indirect measurement of suction and knowledge or some assumption on the soilwater characteristic curve. A detailed description of these methods is beyond the scope of the paper. The motivation behind the work presented in the paper was the investigation of the performance and accuracy of various smallsize sensors currently available on the market with the intention to use them in the quality control of earthworks, more specifically earth dams. Various types of soils regarding grain-size distribution, plasticity and origin can be found in all types of earthworks. It is earth dams however that such a broad range of materials is found in the very same project, with all these materials requiring

\footnotetext{
${ }^{\mathrm{a}}$ Corresponding author: mbardanis@edafos.gr, $\underline{\text { lab@edafos.gr }}$
}

strict quality control, at a rate of testing and accuracy that will not inhibit construction rate or jeopardise safety. Perhaps the most common quality control test is the insitu measurement of density and water content in order to investigate whether they satisfy the requirements of the design study or not. Nuclear methods have covered a lot of ground in this particular field, not without a cost however; financial, training, calibration, certification cost, not to mention an intrinsic -though nowadays unjustified- 'allergy' of personnel to methods described as 'nuclear'. More recently, electrical moisture/density gauges have become interesting alternatives, yet again with considerable cost considerations, although with an important advantage: probe size and strength that allows penetration even in coarser and denser materials often encountered in engineering projects. In an attempt to identify possible areas where cheaper sensors could be used with accuracy and efficiency, two types of commercial, off-the-shelf frequency domain reflectometry (FDR) sensors were used in various materials and ranges of densities and moisture contents. The experience gained is presented in this paper.

\section{Penetration ability}

Perhaps the most important requirement of whatever sensors used is the ability to penetrate the soil where a volumetric water content measurement is needed. This requirement was not investigated in a quantitative, but rather in a qualitative manner. Volumetric water content sensor ML-2x of Delta-T Devices is shown in Fig. 1a. It 

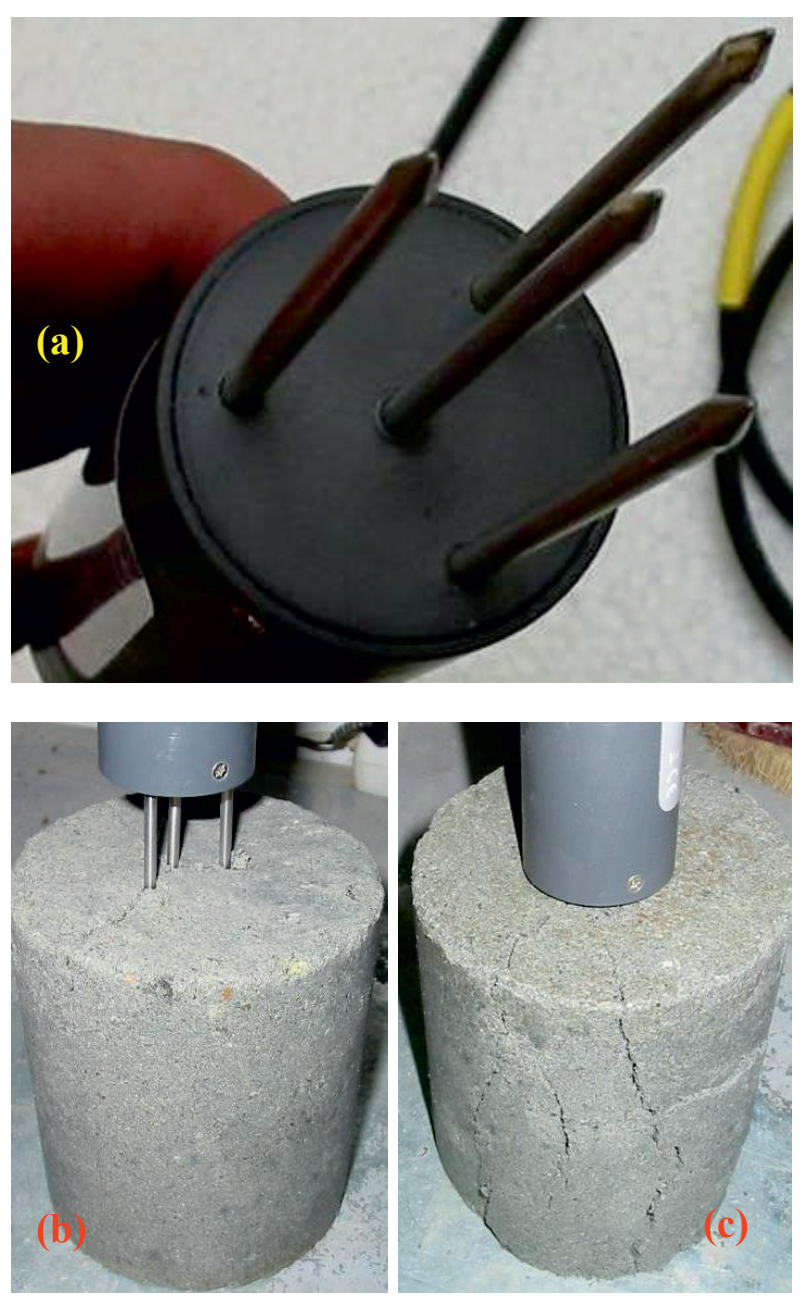

Figure 1. a) Empty plastic tube, cut to receive the MPS-2 sensor (green plasteline used to replaced the part of the tube.

was used in combination with the sand-cone density method for in-situ measurements of density and gravimetric water content as part of the quality control programme during the construction of the Ferekambos river dam on the island of Skiros, Greece. The shoulders of this dam are constructed of a compacted weathered serpentinite found locally in abundance $\left(\mathrm{w}_{\mathrm{L}}=27 \%, \mathrm{I}_{\mathrm{p}}=8\right.$, $\mathrm{G}_{\mathrm{s}}=2.61, \mathrm{w}_{\mathrm{opt}}=11 \%, \gamma_{\mathrm{d} \text {,max }}=19.3 \mathrm{kN} / \mathrm{m}^{3}$ ). The properties of this material have been thoroughly investigated $[1,2]$ and actual samples may be seen in Fig. 1b and c. Compacted samples of the material were prepared in the laboratory at the required dry unit weight $(98 \%$ of the maximum dry unit weight obtained using the Proctor compaction test with standard energy) but dry, at and wet of optimum and the ML-2x sensor was used in each of the samples. The sensor was inserted relatively easily in the sample compacted wet of optimum, could not be inserted in the sample compacted at dry of optimum (Fig. 1b: insertion could not exceed more than $50 \%$ the length of the rods, by that length having already cracked the specimen) and only at the application of very large force was it inserted in the sample compacted at optimum moisture content, again however causing it to crack (Fig. 1c). Obviously therefore there is the need for a sensor of design and construction allowing the application of force sufficient for penetration of the rods in compacted samples, perhaps with mechanical means as well and not just by hand as this makes the use of the sensor not practical in most of the times.

Pre-drilling of pilot holes has been used with many sensors [indicatively 3]. This is an interesting approach which has been found to yield the same readings during comparisons between measurements on the same soil with the sensor inserted by applying force and by pushing the sensor in pre-drilled holes [3]. Also it has been found that for compressible soils, pre-drilling of pilot holes may in fact be the insertion method yielding more accurate measurements [4]. Still it must kept in mind that the motivation behind the findings presented in this paper is whether volumetric water content sensors could be used as a useful alternative during quality control of the construction of earthworks and especially earth-dams, enhancing speed of testing without compromising accuracy. It is the author's experience that the additional time and effort of pre-drilling pilot holes for the sensor rods essentially renders their use strenuous enough to inhibit the required rates of testing during quality control of compaction of geomaterials.

\section{Effect of large-size grains}

Another factor contributing directly to the penetration ability is the presence of large-size grains. It should be born in mind that even if there is interest only in the material of clay cores, as many specifications allow (for instance [5]) the fraction of large-size grains can be high (indicatively a material containing only $20 \%$ of plastic fines, and coarser grains smaller than $76 \mathrm{~mm}$ can be used as material for the construction of a "clay" core provided it has plasticity index $\left.I_{p}>7,[5]\right)$. Obviously fractions of coarse grains of this magnitude can inhibit the insertion of the rods of volumetric water content sensors.

Except for this direct effect of large-size grains, their indirect effect on the volumetric water content of finegrained soils with sporadic presence of coarse grains was investigated. The material used to construct the clay core of the aforementioned Ferekambos dam on Skiros island, Greece, was used. This is a a clayey silt with sand $\left(\mathrm{w}_{\mathrm{L}}=44 \%, \mathrm{I}_{\mathrm{p}}=21, \mathrm{G}_{\mathrm{s}}=2.67, \mathrm{w}_{\mathrm{opt}}=23 \%, \gamma_{\mathrm{d}, \max }=16 \mathrm{kN} / \mathrm{m}^{3}\right)$. Compacted samples of the material in the range very wet of optimum ( $\mathrm{w}=30 \%, 7 \%$ higher than optimum moisture content) were prepared and their initial volumetric water content was measured using the GS-3 frequency domain reflectometry (FDR) sensor by Decagon Devices Inc. Once initial values were obtained, compacted samples were cut vertical to their axis and fully saturated disks of various rocks and thicknesses were placed in the cut compacted samples. The gap around the periphery of the rock disks was covered with material of the same density and water content of the compacted samples and the volumetric water content was measured again, placing the sensor in a way that the rock disk was positioned in the middle of the distance between two of the three rods of the sensor. This sensor is shown in Fig. 2a, a disk of limestone placed in a cut compacted sample is shown in Fig. $2 b$, the sensor inserted for measurement in a sample containing a rock disk is shown in Fig. $2 \mathrm{c}$, and a 

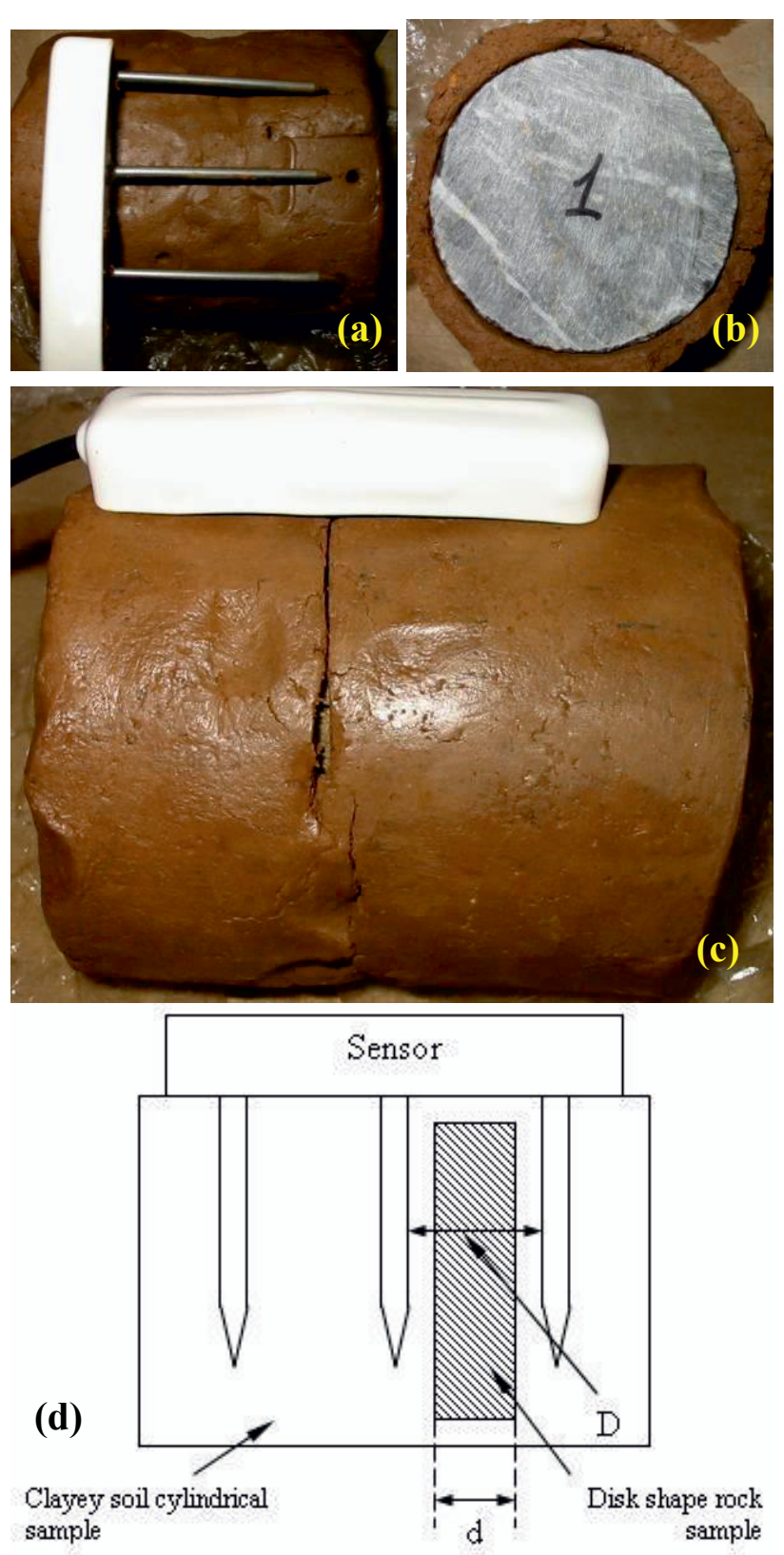

Figure 2. a) The GS-3 sensor before insertion, b) a disk of limestone inserted in the sample, c) insertion of the sensor in a compacted sample containing a rock disk, and d) schematic of the insertion of rock disks and definitions of $d$ and $D$.

schematic of the insertion of rock disks in the compacted samples is shown in Fig. 2d. It is pointed out that measurements in the material of the samples prior to the insertion of the sensor were also performed on larger volume samples and no statistically significant differences were found in the measurements indicating that there are no boundary effects influencing measurements during this type of insertion of the sensor.

The results of this series of measurements are plotted in Fig. 3. Five different types of rock were used; sandstone, limestone, marble, granite and gneiss. Volumetric water content $\theta$ is plotted against the thickness of rock disks $d$ in Fig. 3a. $\theta$ generally decreases with increasing rock disk thickness as expected due to smaller volumetric water content of the rock disks. It is notable that there seems to be a common trend
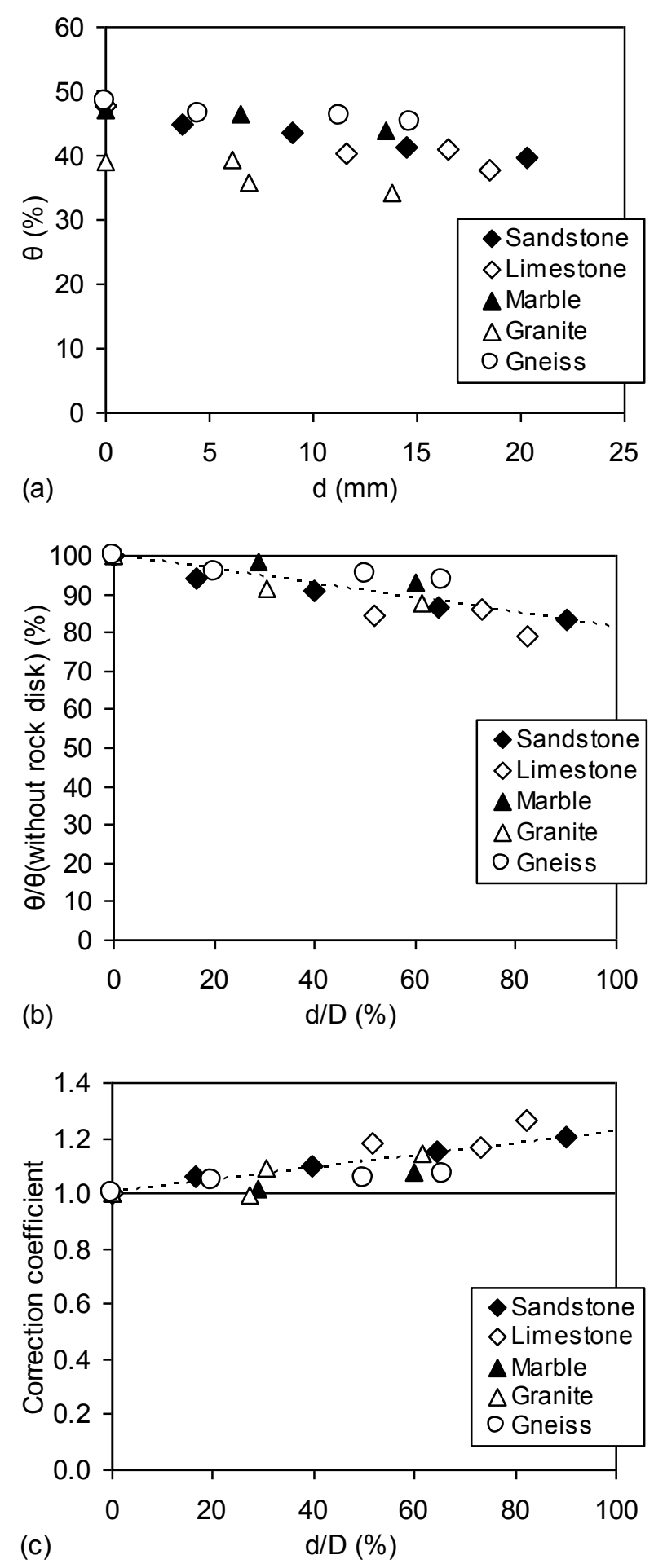

Figure 3. a) Volumetric water content $\theta$ vs rock disks' thickness $\mathrm{d}, \mathrm{b}$ ) volumetric water content over that of the initial sample vs the ratio of rock disks' thickness over rods' distance, $\mathrm{D}$, and c) correction coefficient of volumetric water content of sample in the presence of rock disks for five different types of rock vs the ratio of rock disks' thickness over rods' distance, D.

irrespective of the rock type. Volumetric water content was then normalized by dividing it with its initial value measured on the compacted samples before insertion of the rock disks $\left(\theta_{\mathrm{i}}\right)$ and the thickness of rock disks was normalized by dividing with the distance between the rods of the sensor D. Normalised results are plotted in 
Fig. 3b. Again there seems to be a common trend irrespective of the rock type and $\theta / \theta_{i}$ decreases with increasing $d / D$ according to Equation 1 (obtained for all the results irrespective of the rock type). If one reverses $\theta / \theta_{\mathrm{i}}$ in order to obtain a correction coefficient with the $\mathrm{d} / \mathrm{D}$ ratio, then the results are plotted in Fig. $3 \mathrm{c}$, and Equation 2 yields the correction coefficient $\mathrm{a}_{\theta}$ with ratio $\mathrm{d} / \mathrm{D}$ used in Equation 3. Equations 1 and 2 may by no means be generalised in any respect. Still, this series of measurements and the formulation of Equations 1 and 2 can serve as a guide for investigating the effect of the sporadic presence of coarse grains in predominantly finegrained materials and the way of correcting measurements with volumetric water content sensors.

$$
\begin{gathered}
\theta / \theta i=100-0.187 \cdot d / D \\
a_{\theta}=1+0.0022 \cdot d / D \\
\theta_{\text {corrected }}=a_{\theta} \cdot \theta_{\text {measured }}
\end{gathered}
$$

\section{Indirect effect of density and effect of sample receivers}

Except for the direct effect of density on penetration ability, the indirect effect due to the corresponding mechanical behaviour of soils was investigated. In an attempt to use the ML-2x sensor of Delta-T Devices in the quality control of the construction of the Ferekambos dam, the particular device was tested on compacted samples of the Skiros weathered Serpentinite used for the construction of the shoulders of the dam and part of the core. Compacted samples of various densities were prepared for calibration of measurements and these were carried out with the samples still in the moulds they were compacted in (Fig. 4a) and after they were extruded (Fig. 4b) with samples always covered with cling film to avoid drying. As these samples were relatively small $(10 \mathrm{~cm}$ high by $10 \mathrm{~cm}$ in diameter) one much larger sample in diameter was prepared (Fig. 4c). In order to compare the effect of the presence of the mould with the previous measurements, another sample was prepared with a mould placed around the position where the sensor was measuring (Fig. 4d). Density of the samples was controlled by means of the number of strokes per layer for each of the three layers used to compact the samples. $8,16,25$ and 50 strokes were used yielding dry unit weights between 16.7 and $17.8 \mathrm{kN} / \mathrm{m}^{3}$. Measurements immediately after insertion of the sensors were recorded along with measurements after considerable time until readings were stable.

The measurements are presented in Fig. 5. In all cases, the sensor measured smaller values of volumetric water content when the sample had been extruded from the mould. The same was observed when the mould was placed in the larger sample, indicating that the metal of the moulds has the effect of increasing the measured value of volumetric water content. Smaller size of samples on the other hand increases the measured values as observed for a sample of the larger size sample that was trimmed and removed (denoted 'Air' in Fig. 5). The soil used in this series of measurements exhibits dilation
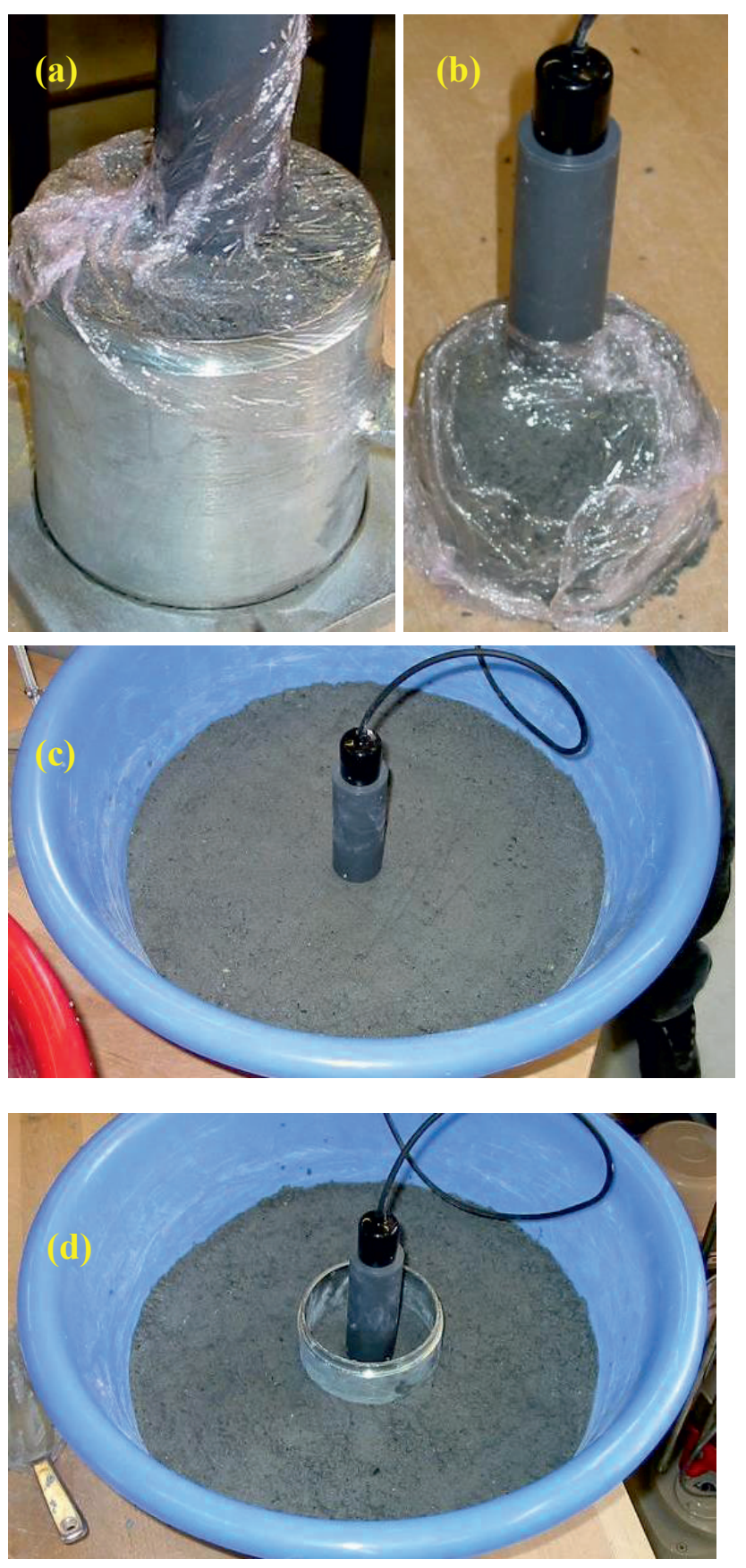

Figure 4. Samples of compacted Skiros weathered serpentinite with the ML-2x probe inserted for volumetric water content measurement a) still in the Proctor test compaction mould, b) after extrusion, c) of larger diameter, and d) of larger diameter but with the mould placed too.

during shear [2] for the densities the samples had. The insertion of sensor rods resembles shear and it is expected therefore to cause dilation of the soil in the vicinity of the sensor rods. Around the rods therefore there is a volume increase which results in attracting moisture from the soil lying further away. This causes the measured volumetric water content to increase with time as was observed (Fig. 5 ). This was not observed so clearly on the sample of the larger size sample that was trimmed and removed (denoted 'Air' in Fig. 5) as it must have been disturbed, and was not observed at all in the larger diameter sample. The latter cannot be clearly expected, yet this was the 


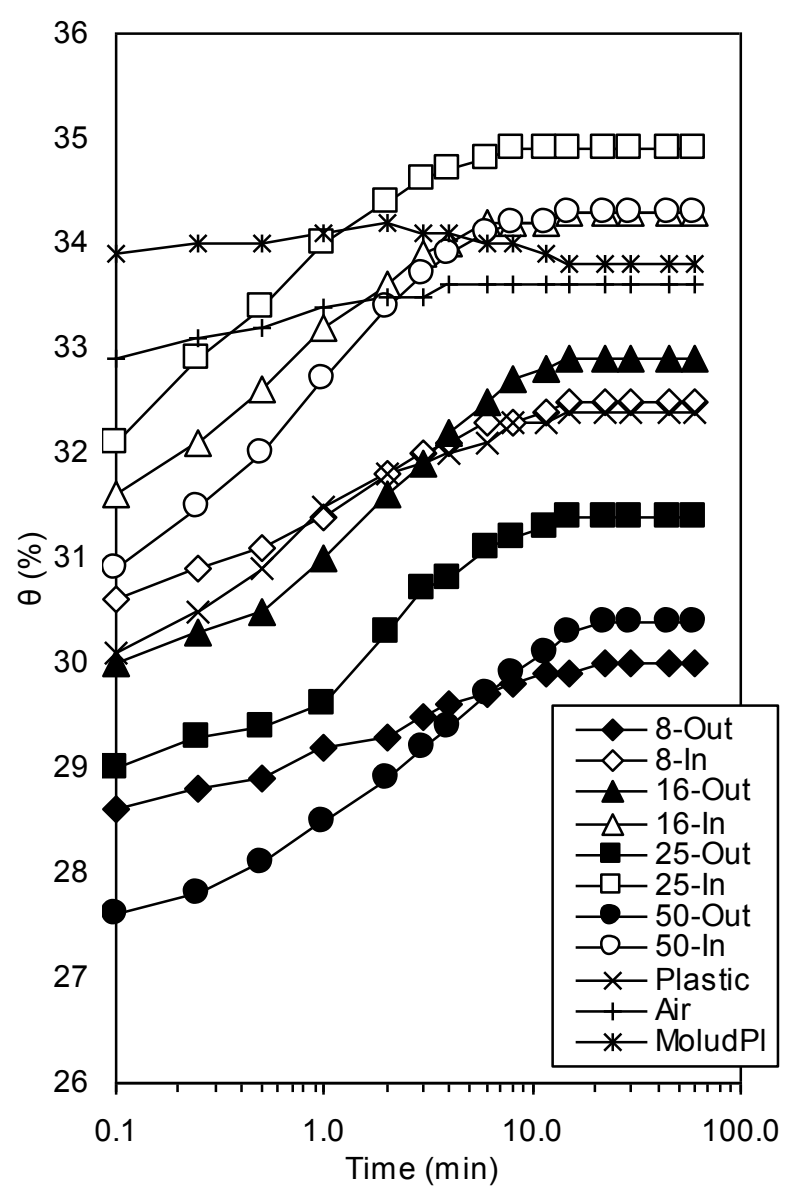

Figure 5. Volumetric water content measured with the ML-2x probe vs time after insertion of the probe in the samples of compacted Skiros weathered serpentinite. Number denotes the number of strokes, 'out' and 'in' that the sample was extruded from the mould or not respectively, 'plastic' the larger sample prepared, 'MouldPl' the larger sample with the mould placed too, and 'air' the sample trimmed from the larger sample without the mould.

most complicated sample to prepare of all samples and uncontrolled variations of densities and water content during preparation cannot be ruled out.

\section{Calibration checks}

The values of volumetric water content measured during this series of measurements were used in combination with the known volume of each sample and its total mass (exactly the same data available after performing a sand cone density test) to calculate the gravimetric water content and the dry unit weight of the samples (properties required during construction in order to decide whether to proceed with the next layer or not). Both measurements immediately after insertion and after stabilisation for samples inside and outside the moulds were used in these calculations and they were compared to the values obtained after actually measuring the gravimetric water content. These comparisons are shown in Fig. 6a for gravimetric water content and Fig. 6b for dry unit weight. As exhibited by these measurements, volumetric water
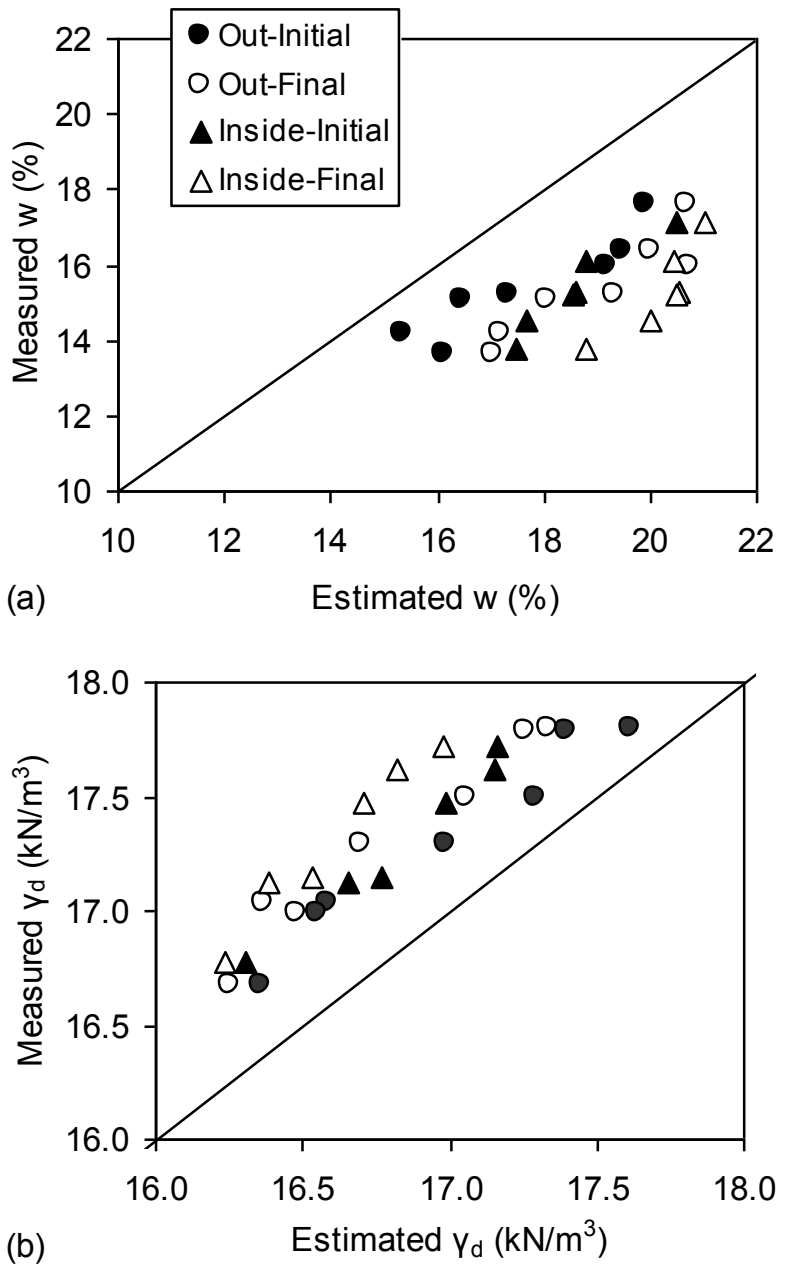

Figure 6. a) Measured vs estimated gravimetric water content, and b) measured vs estimated dry unit weight for samples of compacted Skiros weathered serpentinite from 'initial' and 'final' measurements performed with the ML-2x probe with the samples 'inside' the compaction moulds and 'out' of them.

content readings immediately after insertion on samples extruded from their samples yield the values of gravimetric water content and dry unit weight closest to the actually measured values. In the case of the dry unit weight deviation was only $1-3.5 \%$ of the measured value with the estimated value being in all cases smaller than the measured value by this magnitude which is on the safe side. For gravimetric water content estimated values were always larger than the measured values by $8-16 \%$ of the measured value. Perhaps the most important conclusion from this series of calibration checks for a material exhibiting dilation during insertion of the probe rods (as is usually the case in most compacted materials used in earth-dam construction), is the importance of using readings immediately after insertion as they yield estimations of gravimetric water content and dry unit weight (when combined with measurements of total volume and total mass, as in the case of the sand cone density test) closer to true values. Despite the disadvantage of small probes that are usually pushed in the ground by hand that there may be occasions of very dense and dry soils that they will not penetrate the soil; still, if they do penetrate, they have the advantage of 
yielding readings immediately compared to larger sensors with bigger rods that take more time to actually insert the rods in the ground and their readings will most likely be affected by dilation of soil around the rods.

\section{An example of use}

The ML-2x sensor was used in the quality control of the construction of the Ferekambos dam, especially during construction of the shoulders of the dam from Skiros weathered Serpentinite. It was used in combination with in-situ measurements of density by the sand-cone method and measurements of gravimetric water content by placement in the $110{ }^{\circ} \mathrm{C}$ oven. The idea behind its extensive use was that rather than waiting to obtain the gravimetric water content some time after retrieving the sample from the site and putting it into the oven, combine the measured value of volumetric water content on the soil of the in-situ test with the total volume and total mass known immediately after performing the sand cone test to obtain an estimation of gravimetric water content and dry unit weight. These estimations were not used during construction of the particular dam to take decisions on whether to proceed with construction of the next layer or not but rather in order to evaluate possible use of this method for future use. Comparison between measured and estimated values of gravimetric water content and dry unit weight are shown in Fig. $7 \mathrm{a}$ and $7 \mathrm{~b}$ respectively. " $1=1$ " lines are plotted for reference along with best-fit regression lines and for comparison the calibrations obtained on the same material from measurements of volumetric water content immediately after insertion of sensors in laboratory compacted samples extruded from their moulds. In both cases, points scatter practically equally around the " $1=1$ " lines. Scatter was much larger for gravimetric water content $(-45$ to $+70 \%$ of the measured values) and a best-fit line did not lie close to the " $1=1$ " line. On the other hand scatter was very low for dry unit weight; only -4.6 to $+5.3 \%$, indeed a very low scatter allowing one to rely on this method for decisions regarding the dry unit weight of a compacted layer. It is notable how close the best-fit line lies to the " $1=1$ " line.

\section{Conclusions}

Small-size volumetric water content sensors were used for various calibration tests on compacted soils used in the construction of earth-dams. Penetration ability of the sensors' rods is the first and foremost requirement. Sporadic presence of coarser grains decreases large values of volumetric water content and the need for an order of magnitude of the appropriate correction of measurements needs to be known if materials like that are encountered. Calibration checks revealed that the estimations of gravimetric water content and dry unit weight closest to their measured values are obtained by use of readings of volumetric water content taken immediately after insertion of the sensors in laboratory compacted samples extruded from their moulds. Comparison between measured and estimated gravimetric water content and dry unit weight on the basis of volumetric water content measured in-situ and combined with sand-cone density tests revealed that estimated values of dry unit weight are very close to the measured ones unlike gravimetric water content values.
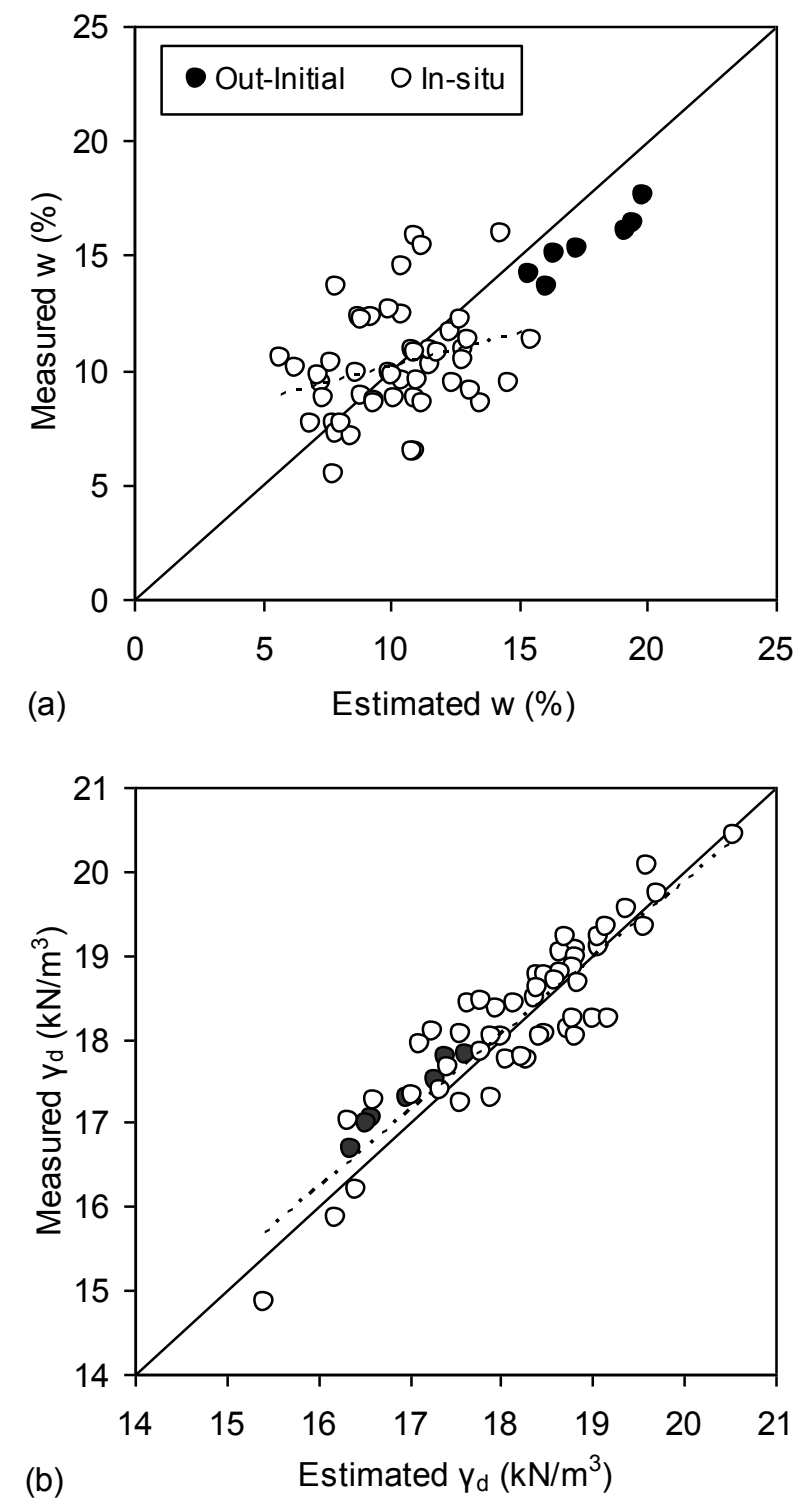

Figure 7. Measured vs estimated a) gravimetric water content, and b) dry unit weight from combination of volumetric water content measurements and sand-cone tests on compacted Skiros weathered Serpentinite during construction of the Ferekambos dam. Solid lines are " $1=1$ " lines, dashed ones are best-fit.

\section{References}

1. M. E. Bardanis, S. Grifiza, proc. 5th Int. Conf. Unsaturated Soils, Barcelona, Spain, 2010, 1, 187-192.

2. M. E. Bardanis, S. Grifiza, proc. 6th Hel. Conf. on Geotech. and Geoenvironmental Engineering, Volos, 29 September - 1 October, 2010, Vol. 1, pp. 151-158.

3. G. C. Topp et al., Soil Sci. Soc. Am. J. 46 (1982) 678-684.

4. A. Rothe et al., Water Resour. Res., 3 (1997) 15851593.

5. Hellenic Technical Specification 1501-13-01-01-00, Impervious core of zoned earth and rockfill dams. 